\title{
Chapter 11 \\ Emerging Socio-Economic and Environmental Issues Affecting Food Security: A Case Study of Silang-Santa Rosa Subwatershed
}

\author{
Roberto F. Rañola Jr., Fe M. Rañola, Maria Francesca O. Tan, \\ and Ma. Cynthia S. Casin
}

\begin{abstract}
The Silang-Santa Rosa subwatershed feeds into Laguna Lake to the south-east of Metro Manila. This case study of the subwatershed provides some insights on the interactions between people and institutions within their given natural environment. The link between the socio-economic conditions of households and the quality of the ecosystem resources available is premised on the extent to which socio-economic conditions influence household decisions relating to the use and management of land and water resources. The major issue is how people might be able to improve, protect, and expand their current resource base or level of acquirement given the different types of risks they face. In the subwatershed's upstream areas, the risk is from soil degradation coupled with inefficient farm production systems that lead to low farm productivity. In the downstream areas, households face poverty-related issues such as food insecurity and low income from declining fishery resources. In addition, pollution from both upstream and downstream areas threatens their livelihoods and increases the incidence of water-borne diseases. To address these issues, it is proposed that the different stakeholders could be enlisted to develop an integrated development plan that would reflect their common interests and vision for the watershed area feeding into Laguna Lake. The plan should deal with major issues such as land and water degradation, poverty, livelihoods, food security, health, farm production efficiency, and marketing systems, as well as regulatory and economic instruments that would reduce land and water degradation.
\end{abstract}

Keywords Farm income $\bullet$ Food security $\bullet$ Global environmental change

\footnotetext{
R.F. Rañola Jr. $(\varangle) \bullet$ F.M. Rañola • M.F.O. Tan

Department of Agricultural Economics, College of Economics and Management, University of the Philippines Los Baños, Los Baños, Philippines

e-mail: bert1866@gmail.com; fkm1866@yahoo.com; france.tan.315@gmail.com

M.C.S. Casin

Forestry Development Center, College of Forestry and Natural Resources,

University of the Philippines Los Baños, Los Baños, Philippines

e-mail: chingcasin@yahoo.com
} 


\subsection{Introduction}

Food systems and food security are greatly affected by environmental changes such as land degradation, loss of biodiversity, and alteration in hydrology or climate patterns. These changes may be either natural or anthropogenic in origin, although it is the alterations of anthropogenic origin that contribute most to environmental change. Food systems include activities such as food production, processing, packaging, and distribution and retailing. They are complex systems influenced by environmental, social, and economic factors, and they link directly with policy and public health issues.

Currently, the accepted definition of food security as defined by the International Conference on Nutrition (ICN) is "access by all people at all times to the food needed for a healthy life," [FAO/WHO 1992a, as cited by the Committee on World Food Security of the Food and Agriculture Organization (Food and Agriculture Organization-Food and Nutrition Division and Publishing Management 1997)]. Food insecurity, on the other hand, is defined as lack of access to enough food for a healthy and active life. According to a definition that had its origins in the 1970s, however, food security refers to the availability, accessibility, utilization, and stability of food supplies (Stamoulis and Zezza 2003, as cited in Springer Editorial 2009).

Food availability is often associated with climatic changes that can affect the agriculture, aquaculture, and forestry sectors. Accessibility, however, depends on the knowledge and resources of households themselves. Such knowledge and resources include strategies utilized by households for food acquisition, that is, their ability to produce food and exchange assets for food. The strategies may include borrowing money, selling assets, or engaging in wage labor to provide food for the family. While neither rural nor urban households are spared from food insecurity, especially during seasonal troughs, the former are able to produce their own food, while the latter purchase most of their foods. The urban households are therefore more affected by food insecurity, especially if jobs are lost, incomes fall, and food prices increase. In terms of utilization, women are usually responsible for food procurement, preparation, and storage, especially in rural areas. Stability of food supply, meanwhile, is defined by use of a set of strategies to cope with both major and minor stresses. Communities that live in stressful environments, in particular, have developed strategies to reduce the impact of environmental stresses on household food security in the short- and/or long term. An important strategy is protection of the resource base through production practices that do not damage the environment to the detriment of the agriculture, fishery, and forestry sectors. An example would be changing cropping systems to increase farm productivity. Another coping strategy is to ensure that the procurement of food does not lead to the loss of a household's capacity to produce using its assets such as land, equipment, and farm animals.

The issue of risks to food security from environmental degradation is of major importance, because the poor are the ones most affected. In rural areas where a high incidence of poverty exists, the rural poor are forced to cultivate fragile and marginal lands causing soil erosion. This renders them very vulnerable to environmental 
risks such as the diminution and contamination of their water supplies, and reduction in farm productivity that has a direct impact on their food security (Food and Agriculture Organization-Food and Nutrition Division and Publishing Management 1997).

This paper seeks to present the impacts of some socio-economic factors and related environmental risks on food security in the Silang-Santa Rosa subwatershed. A good understanding of this link is a crucial step in developing strategies for addressing food security.

\subsection{Conceptual Framework}

Food security is affected by a number of socio-demographic and environmental conditions in the Silang-Santa Rosa subwatershed (Fig. 11.1). The current environmental condition of the subwatershed is primarily the result of anthropogenic activities extending from the upstream communities to those downstream. Environmental risks that are major threats to food security in the Silang-Santa Rosa subwatershed include land conversion, soil degradation, and consequent soil erosion. An additional threat is the increase in pollution resulting from urbanization and an expanding population. These environmental factors can affect the livelihood of dwellers residing within the community, who are primarily dependent on farming and fishery to make a living. Moreover, since individual sources of livelihood determine the amount of food that can be produced, as well as the additional income that can be generated to purchase food, socio-demographic characteristics such as age and educational attainment also have a major influence on the food security of individuals.

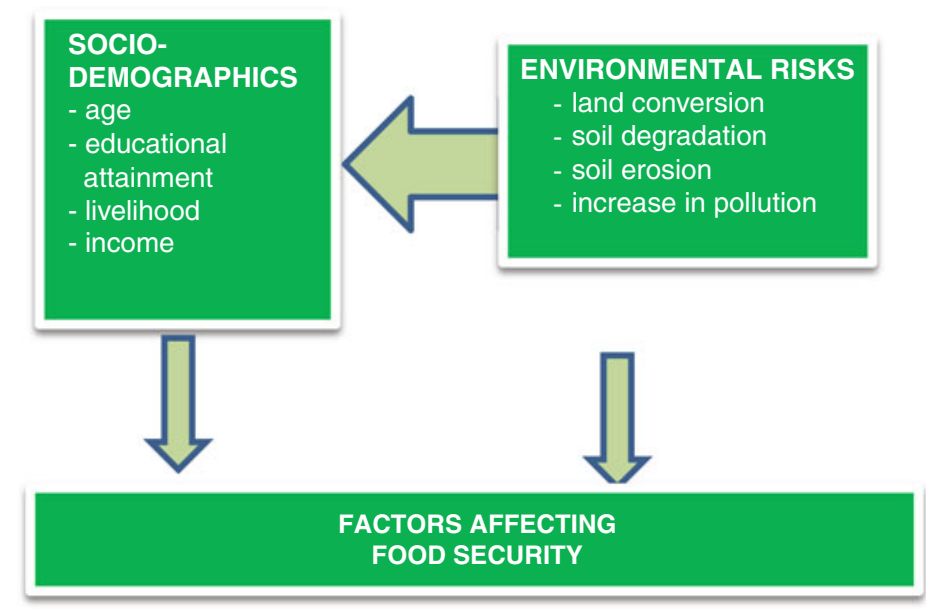

Fig. 11.1 Conceptual framework of food security in Silang-Santa Rosa subwatershed 


\subsection{Study Site}

The research sites were classified into three types of watershed area: upstream (Pulong Bunga), midstream (Tartaria), and downstream (Santo (Sto.) Tomas and Aplaya) (Fig. 11.2). The slopes in the upstream area range from 8 to $18 \%$.

The barangay (district) of Pulong Bunga is an agricultural community located in the upstream municipality of Silang in Cavite Province, near the municipality of Tagaytay. Tartaria, in the midstream area, is another agricultural community in Silang, and portions of its tributaries feed into the downstream municipality of Santa (Sta.) Rosa. According to responses obtained during farmer interviews, there are plans by some private developers to convert the agricultural areas of this barangay into built-up areas. The downstream study sites comprise the barangays of Sto. Tomas and Aplaya, located in the Laguna Province municipalities of Biñan and Sta. Rosa, respectively. They are regularly flooded and considered to be environmentally critical zones. Fishing is a major source of income in these districts.

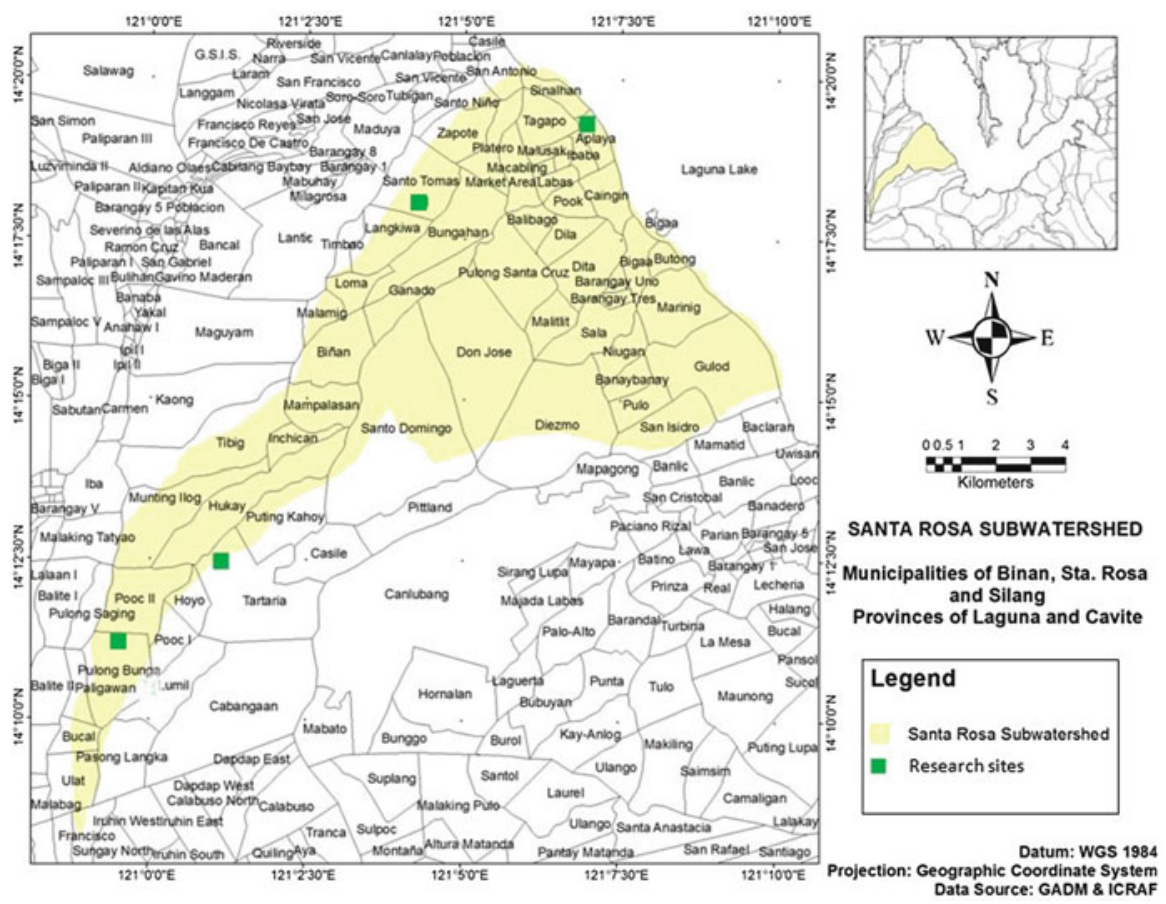

Fig. 11.2 Map of the Silang-Santa Rosa subwatershed 


\subsection{Results and Discussion}

This section provides a summary of household circumstances in the upstream, midstream, and downstream topographical locations within the Silang-Santa Rosa subwatershed. This is important for gaining a good understanding of how environmental risks or factors affect the incidence of poverty and food insecurity in the subwatershed.

\subsubsection{Socio-Demographic Characteristics}

The socio-demographic characteristics and conditions of farmers and fishermen have a major influence on their vulnerability to natural and anthropogenic hazards, their use and management of land and water resources, and their adaptation strategies to cope with these hazards. This has an effect on their livelihoods, incomes, food security, and health.

Table 11.1 shows the socio-demographic characteristics of households. The upstream and downstream residents of the watershed are relatively homogenous in

Table 11.1 Household characteristics of respondents surveyed, Silang-Santa Rosa subwatershed, 2013

\begin{tabular}{|c|c|c|c|c|}
\hline & Upstream & Midstream & Upper downstream & Lower downstream \\
\hline Characteristics & $\begin{array}{l}\text { Pulong Bunga } \\
(\mathrm{n}=39)\end{array}$ & Tartaria $(n=39)$ & Sto. Tomas $(n=42)$ & Aplaya $(\mathrm{n}=19)$ \\
\hline Cultural origin & $77 \%$ Native & $31 \%$ Native & $90 \%$ Native & $100 \%$ Native \\
\hline & $23 \%$ Migrant & $69 \%$ Migrant & $10 \%$ Migrant & \\
\hline Average age & & & & \\
\hline Household head & 51 & 49 & 42 & 47 \\
\hline Spouse & 42 & 34 & 38 & 45 \\
\hline Household size & & & & \\
\hline Range & $2-10$ & $2-10$ & $2-10$ & $3-7$ \\
\hline Mean & 5 & 5 & 5 & 5 \\
\hline Type of family & $67 \%$ Nuclear & $74 \%$ Nuclear & $74 \%$ Nuclear & $68 \%$ Nuclear \\
\hline & $33 \%$ Extended & $26 \%$ Extended & $26 \%$ Extended & $32 \%$ Extended \\
\hline Education & & & & \\
\hline Household head & $\begin{array}{l}23 \% \text { Primary and } \\
\text { Intermediate }\end{array}$ & $\begin{array}{c}37 \% \text { Primary and } \\
\text { Intermediate }\end{array}$ & $\begin{array}{l}30 \% \text { Primary and } \\
\text { Intermediate }\end{array}$ & $\begin{array}{l}22 \% \text { Primary and } \\
\text { Intermediate }\end{array}$ \\
\hline & $38 \%$ Secondary & $35 \%$ Secondary & $59 \%$ Secondary & $56 \%$ Secondary \\
\hline & $38 \%$ Tertiary & $29 \%$ Tertiary & $11 \%$ Tertiary & $22 \%$ Tertiary \\
\hline & $1 \%$ Postgraduate & & & \\
\hline Spouse & $\begin{array}{l}30 \% \text { Primary and } \\
\text { intermediate }\end{array}$ & $\begin{array}{c}27 \% \text { Primary and } \\
\text { intermediate }\end{array}$ & $\begin{array}{l}40 \% \text { Primary and } \\
\text { intermediate }\end{array}$ & $\begin{array}{l}11 \% \text { Primary and } \\
\text { intermediate }\end{array}$ \\
\hline & $30 \%$ Secondary & $46 \%$ Secondary & $56 \%$ Secondary & $78 \%$ Secondary \\
\hline & $40 \%$ Tertiary & $27 \%$ Tertiary & $4 \%$ Tertiary & $11 \%$ Tertiary \\
\hline
\end{tabular}


their cultural origins. In the lower downstream barangay of Aplaya, all residents are native to the district, while in the upper downstream area of Sto. Tomas, and the upstream area of Pulong Bunga, $90 \%$ and $77 \%$, respectively, are native to their districts. In the midstream area of Tartaria, however, the majority (69\%) are migrants, having migrated within their own municipality from other barangays in Silang, or from neighboring Batangas Province.

Most of the respondents are still in their productive years, with average ages of 42 and 47 in the downstream areas of Sto. Tomas and Aplaya, respectively, and average ages of 51 and 49 in Pulong Bunga and Tartaria. Family sizes in Aplaya households are relatively small, ranging from 3 to 7 members, compared to the bigger families of 2 to 10 in Sto. Tomas, Tartaria, and Pulong Bunga.

The literacy rate is high in the study areas. Among household heads in the downstream areas of Sto. Tomas and Aplaya, $59 \%$ and $56 \%$, respectively, have reached or finished the secondary level of education. In addition, $56 \%$ of spouses in St. Tomas and $78 \%$ of spouses in Aplaya have reached or finished secondary education. In the midstream area, household heads and their spouses have attained higher levels of education, with $29 \%$ and $27 \%$, respectively, having reached the tertiary level of education. This also holds true in the upstream barangay, where $38 \%$ of household heads and $40 \%$ of spouses have reached or earned college degrees.

\subsubsection{Labor Resources}

The available labor resources can be the most important family asset for the upstream and midstream agricultural households as well as the downstream fishing households. Across sites, the households are predominantly nuclear families whose heads are engaged in farming and fishing activities. The contribution of family labor in farming and fishing, however, is limited. Across sites, the percentages of women that remain at home as housewives are: $40 \%$ of women in upstream areas, $60 \%$ in midstream areas, $62 \%$ in upper downstream areas, and $44 \%$ in lower downstream areas. The rest are either engaged in trading daily goods, selling ornamental plants, or are employed as workers in factories and offices. Other family members who are not gainfully employed provide additional sources of unpaid family labor in farms. To cope with increasing household expenses, the majority of household heads in the upstream and midstream areas have a secondary occupation, with $35 \%$ and $31 \%$ engaged in transport and construction work, respectively. In the downstream sites, meanwhile, only $13 \%$ in Sto. Tomas and $11 \%$ Aplaya, have secondary employment(Table 11.2).

\subsubsection{Household Financial Status}

In the upstream area, the average annual income for a family of five is PHP 52,508. Given that in 2009 the NSCB (National Statistical Coordination Board 2009) estimated the household poverty threshold at an annual income equal to or less than 
Table 11.2 Employment status of households in Silang-Santa Rosa subwatershed, 2013

\begin{tabular}{|c|c|c|c|c|}
\hline Employment/occupation & $\begin{array}{l}\frac{\text { Upstream }}{\text { Pulong Bunga }} \\
(\mathrm{n}=39)\end{array}$ & $\begin{array}{l}\frac{\text { Midstream }}{\text { Tartaria }} \\
(\mathrm{n}=39)\end{array}$ & $\begin{array}{l}\begin{array}{l}\text { Upper } \\
\text { downstream }\end{array} \\
\begin{array}{l}\text { Sto. Tomas } \\
(\mathrm{n}=42)\end{array}\end{array}$ & $\begin{array}{l}\begin{array}{l}\text { Lower } \\
\text { downstream }\end{array} \\
\text { Aplaya } \\
(\mathrm{n}=19)\end{array}$ \\
\hline \multicolumn{5}{|l|}{ Household head } \\
\hline \multicolumn{5}{|l|}{ Primary } \\
\hline Farmer $(\%)$ & 33 & 33 & 7 & \\
\hline Fisherman $(\%)$ & & & & 16 \\
\hline \multicolumn{5}{|l|}{ Secondary } \\
\hline $\begin{array}{l}\text { Goods trader, wage worker, } \\
\text { driver, or construction } \\
\text { worker }(\%)\end{array}$ & 35 & 31 & 13 & 11 \\
\hline \multicolumn{5}{|l|}{ Spouse } \\
\hline Homemaker (\%) & 40 & 60 & 62 & 44 \\
\hline $\begin{array}{l}\text { Store owner, goods trader, } \\
\text { wage worker, or ornamental } \\
\text { plant seller }(\%)\end{array}$ & 60 & 40 & 38 & 56 \\
\hline
\end{tabular}

Table 11.3 Households' financial status in 2013, based on latest NSCB report of 2009

\begin{tabular}{|c|c|c|c|c|}
\hline & Upstream & Midstream & Upper downstream & $\begin{array}{l}\text { Lower } \\
\text { downstream }\end{array}$ \\
\hline Financial status & $\begin{array}{l}\text { Pulong Bunga } \\
(\mathrm{n}=39)\end{array}$ & $\begin{array}{l}\text { Tartaria } \\
(\mathrm{n}=39)\end{array}$ & Sto. Tomas $(n=42)$ & Aplaya $(n=19)$ \\
\hline $\begin{array}{l}\text { Average annual household } \\
\text { income }\end{array}$ & PHP 52,508 & PHP 43,688 & PHP 22,396 & PHP 20,886 \\
\hline $\begin{array}{l}2009 \text { NSCB household } \\
\text { poverty threshold }\end{array}$ & PHP 20,163 & PHP 20,163 & PHP 17,295 & PHP 17,295 \\
\hline$\%$ Below poverty threshold & 15 & 21 & 48 & 63 \\
\hline
\end{tabular}

PHP 20,163, the poverty incidence in the upstream is estimated at $15 \%$. Meanwhile, in the midstream areas, with an average annual income of PHP 43,688 for a family of five, poverty incidence is estimated at $21 \%$. Both these estimates are low compared to the estimated poverty incidences in the downstream sites. In Sto. Tomas, with an average annual income of PHP 22,396 for a family of five, the poverty incidence is estimated at $48 \%$, while in Aplaya, with an annual income of PHP 20,886 , poverty is estimated at $63 \%$ (Table 11.3). These figures do not differ significantly from the figures in the 2009 report by the NSCB, indicating that the economic conditions of fishermen and farmers have been deteriorating. Fishermen posted the highest poverty incidence $(41.4 \%)$, followed by farmers $(36.7 \%)$.

\subsubsection{Land-Based Productive Resources}

On average, each household in the upstream barangay of Pulong Bunga and the midstream barangay of Tartaria is cultivating 1 or 2 parcels of land, respectively. 
Table 11.4 Land-based productive resources: farm holdings, land tenure, and farm distance in Pulong Bunga and Tartaria, Cavite Province, 2013

\begin{tabular}{|c|c|c|c|c|}
\hline \multirow[b]{3}{*}{ Total farm area (ha) } & \multicolumn{4}{|c|}{ Upstream and midstream Barangays } \\
\hline & \multicolumn{2}{|c|}{ Pulong Bunga $(\mathrm{n}=15)$} & \multicolumn{2}{|c|}{ Tartaria $(n=15)$} \\
\hline & No. & $\%$ & No. & $\%$ \\
\hline$\leq 1.0$ & 11 & 58 & 10 & 67 \\
\hline $1.1-2.0$ & 7 & 37 & 5 & 33 \\
\hline 6.0 & 1 & 5 & & \\
\hline Mean & 0.91 & & 1.13 & \\
\hline Range & $0.05-6$ & & $0.5-1.5$ & \\
\hline Sub-total & 19 & 100 & 15 & 100 \\
\hline Average no. of parcels & 1 & & 2 & \\
\hline \multicolumn{5}{|l|}{ Tenurial status } \\
\hline Owned & 17 & 90 & 6 & 40 \\
\hline Rented & 1 & 5 & 9 & 60 \\
\hline Rent-free & 1 & 5 & & \\
\hline Sub-total & 19 & 100 & 15 & 100 \\
\hline \multicolumn{5}{|l|}{ Farm distance to } \\
\hline House & \multicolumn{2}{|c|}{$\leq 1.0(14=74 \%)$} & \multicolumn{2}{|c|}{$\leq 1.0(10=67 \%)$} \\
\hline Road & \multicolumn{2}{|c|}{$\leq 1.0(19=100 \%)$} & \multicolumn{2}{|c|}{$\leq 1.0(9=60 \%)$} \\
\hline Market & \multicolumn{2}{|c|}{$\geq 5.1(5=26 \%)$} & \multicolumn{2}{|c|}{$\geq 5.1(9=60 \%)$} \\
\hline
\end{tabular}

The average land area cultivated in Tartaria is bigger, at $1.13 \mathrm{ha}$, than the 0.91 ha cultivated in Pulong Bunga (Table 11.4). However, $37 \%$ of the farms in Pulong Bunga cover 1.1 to $2.0 \mathrm{ha}$, in contrast to Tartaria, where the corresponding figure is only $33 \%$. A majority (90\%) of the farm lots in Pulong Bunga are privately owned, whereas in Tartaria the majority (60\%) are rented. In Pulong Bunga, however, there is also one household cultivating rented land, and another working land rent-free.

Most of the farms cultivated are very accessible to their owners or cultivators; $60-74 \%$ of farms in Pulong Bunga and Tartaria are located less than a kilometer from their owners' or cultivators' homes. The farms are also close to markets, with an average distance of $5.1 \mathrm{~km}$ or less.

\subsubsection{Emerging Issues}

Three major emerging issues are: (1) the incidence of household food insecurity, (2) declining agricultural and fishery productivity, and (3) environmental risks currently affecting food security.

\subsubsection{Incidence of Household Food Insecurity}

The incidence of household food insecurity may be understood in the context of the "path to food entitlement," and as such, strategies to address the situation are needed. 
The Path to Food Entitlement

Crop losses affect the amount of food available for a family and the amount of food surplus that can be sold for cash to purchase other basic needs. The incidence of food insecurity is therefore influenced by the farming systems adopted (crops grown, number and density of crops, etc.), as well as anthropogenic or biogenic hazards or risks encountered in farm production, and the consequent effect on the family's access to food.

\section{Difficulties in Meeting Household Expenditures}

Across sites, the majority - if not almost all—of the respondents indicated that they have problems or difficulties in meeting their expenses for even the most important household expenditures. These include food (10-58 \%) and farming/fishery inputs (33-69 \%). For all sites, the main reasons for problems in paying for their household needs include the seasonal and irregular flow of income, crop losses from typhoons and seasonal climate variations, the high costs of agricultural inputs, and the difficulty of reducing expenses and making other household adjustments. In the upstream and midstream sites, $44 \%$ are below the 2009 NSCB food poverty threshold of PHP 14,040 for the province of Cavite, while $52 \%$ in the upper downstream site and $26 \%$ in the lower downstream site are below the NSCB food poverty threshold of PHP 12,150 for the province of Laguna. Food expenditures include basic necessities such as rice, fish, sugar, coffee, cooking oil, and in some instances canned goods, flavorings, milk, and meat. Rice is bought by the majority of the households across the watershed. Pandey in his report (2008, as cited in Rañola 2010-2011) indicated that in developing countries like the Philippines, poor people spend $30-50 \%$ of their income on rice. However, with the price of rice increasing by as much as $50 \%$, this means an equivalent drop in their real income of $15-25 \%$, a substantial loss for poor people who are hovering just above the poverty line.

\section{Sources of Entitlement, Risks in Farm/Fishery Production, and Seasonal Food Insecurity}

The ability of households and their members to acquire enough food through production, exchange, or transfer depends on their current sources of entitlement. These include their productive assets, such as their land, tools, and equipment, as well as their farm-related entitlements such as the number or density of crops planted, combinations of crop species, period of harvesting and/or production cycle, total land area for cultivation, and the actual farm size cultivated. Other important sources of entitlement include labor resources, education and health, size of the family, level of income, and nature and sources of income. These factors are related to households' levels of poverty and food poverty thresholds as estimated by the NSCB. However, for households in the Silang Santa-Rosa subwatershed, sources of entitlement are limited, and this is compounded by their regular exposure over time to combinations of farm risks and uncertainty (both natural and anthropogenic). 
It would therefore appear that they are more or less permanently (chronically) vulnerable, rather than being temporarily (transiently) vulnerable. It becomes apparent that under these conditions, households' paths to food entitlement are being threatened or placed at risk.

\section{Indicators of Food Insecurity and Seasonality of Incidence}

Indicators show that households across the subwatershed are at risk of being food insecure. Many respondents indicated that they had experienced food insecurity to some degree, based on the following indicators of household food insecurity: anxiety about having insufficient food, a food deficit resulting from the absence of funds to purchase food, substitution of cheaper but lower quality food items, and reduction of food intake in terms of quantity and quality. That most of the family income is spent on food is indicative of a food-insecure condition. Across sites, $8-31 \%$ of the respondents constantly experience food insufficiency, while another 44-68 \% occasionally have that experience. Approximately $23-100 \%$ of the respondents experience food insufficiency resulting from limited funds to procure food, with the highest percentage of such respondents found in the lower downstream $(100 \%)$. More than half of the respondents state that food on the table for the family is inadequate in quantity and quality and that they substitute cheaper foods while reducing the quantity consumed. This is especially the case in downstream areas, being cited by $79 \%$ and $74 \%$ of respondents in Sto. Tomas and Aplaya, respectively. It can be attributed to factors such as the large size of families, low incomes, and the nature of household income sources. Other factors include the number or density of crops planted, crop species and their combinations, harvesting periods and/or production cycles, total land area available for cultivation, and actual farm size cultivated.

\section{Coping with Food Insecurity}

Across sites, the main strategy used by households to cope with food insecurity problems is to generate sufficient cash from non-farm employment to buy their staple food (as cited by $33 \%$ in the upstream, $54 \%$ in the midstream, $57 \%$ in the upper downstream, and $68 \%$ in the lower downstream areas). To address the problem of insufficient funds, about 44-67\% across sites substituted cheaper but lower quality foods than their regular food items, also reducing their food intake. Farmers in the upstream and midstream, moreover, try to produce nearly all of their own staple food requirements like vegetables and fruit crops. It is apparent, however, that although the households have instituted some measures to address their conditions, these measures reflect the limitations in farm households' assets. For the most part, these adaptive measures are ad hoc and limited in mitigating the impacts of low farm income resulting from the biophysical risks, both natural and man-made, that are inherent in farming. 


\subsubsection{Declining Agricultural and Fishery Production}

Farm households across sites are faced with declining agricultural production. This is attributable to the biophysical traits of their farms, as well as risks associated with typhoons, strong winds, El Niño, and other seasonal climate variations. Socioeconomic and institutional factors have also played a part. The reduced agricultural productivity in farmlands has adversely affected the level of households' farming income. In the upstream, $40 \%$ of farmer respondents stated that their income had declined over the 5 years from 2008 to 2012, with their usual average income of PHP 180,334 dropping by as much as $42 \%$ over the 5-year period. In the midstream, $20 \%$ experienced decreases in income by as much as $58 \%$, in the upper downstream, $50 \%$ cited a decline in production and consequent $50 \%$ decrease in income. In the lower downstream, about $33 \%$ of fishermen in Aplaya experienced a reduction in household income due to diminished fish catches. Their income dropped by as much as $70 \%$ from the usual average annual income of PHP 160,000. Other factors contributing to the decline in fishery income are natural factors such as typhoons, heavy rains combined with strong winds and tidal waves, and polluted water conditions in the lake that contribute to the poor growth of fish.

\subsubsection{Environmental Risks Currently Affecting Food Security}

Farmers and fishermen perceive the risks associated with environmental degradation and its long-term negative consequences as affecting not only themselves but the community as a whole. The risks are of both natural and anthropogenic origins. Those of natural origin include typhoons, strong winds, El Niño, and seasonal variations brought about by climate and/or weather disturbances. In Silang-Santa Rosa, these have the effects of altering the crop cycle, and reducing crop productivity and income. Other types of risks include outbreaks of pests and diseases, crop losses from toxic chemicals, soil erosion and acidity, depressed market prices, and land use conversion.

Farmers and fishermen have faced these risks to some degree for years. However, in the upstream, $46 \%$ claimed that their level of exposure to such risks is low. A low level of exposure was also cited by $25 \%$ in the midstream, $100 \%$ in the upper downstream, and $50 \%$ in the lower downstream. This can be attributed to the respondents' resiliency and the measures they have adopted to address the risks. Factors affecting their level of resiliency include their earning capacity, family assets, and asset management, as well as support from family and relatives that provide financial assistance in times of need. One specific adaptive measure taken in Silang-Santa Rosa is to immediately replant to replace damaged crops. Otherwise farmers simply wait for crops to recover naturally, or go and seek off-farm or nonfarm employment.

However, these adaptive measures are generally makeshift and do little to reduce the impacts of climatic events and other forms of risks. They are also very dependent 
on the level of household assets and resources. According to the respondents, in the longer term these risks will pose a major threat to the income, food security, and health of their families and community. They also mentioned that with a persistently low farm productivity and income, they would be forced to stop sending their children to school, or possibly have no choice but to sell their farmland. Inadequate food supply would also increase the incidence of hunger, malnutrition, and possibly even death. For the community as a whole, it would lead to loss of their crops and farms, and the destruction of their properties.

\subsection{Conclusion}

The incidence of food insecurity can be viewed as the ultimate effect of several inter-related biophysical and socio-economic factors that comprise the main hazards and risks. Environmental degradation, for example, may be caused by a combination of man's interaction with physical resources and naturally occurring hazards. It is evident in all the sites that the declining land resource base is adversely affecting farm and fishery households' incomes and livelihoods, resulting in the threat of food insufficiency for the poorest. Across sites, households perceive that continued occurrence of climatic and other natural events in the years to come will have a major impact on their incomes, family health, food security, and the circumstances of the community as a whole.

With these issues in mind, the following technical and policy concerns should be taken into consideration to develop a research agenda that would facilitate the creation of a plan for managing watersheds and implementing related strategies.

1. Developing an integrated approach to watershed management that covers both land and water resources entails convening the major stakeholders to: (1) develop and agree on a common vision, goals, and objectives for managing the watershed and lake resources (e.g., improved water quality for a given period of time); (2) identify issues and problems that may hinder the fulfilment of the vision, goals, and objectives; and (3) prioritize and develop an agreed action plan for dealing with the identified problems and/or constraints.

2. In trying to address issues relating to soil and land degradation, it is important to determine whether the causes are anthropogenic or geogenic, since the potential solutions would be different. For example, many problems related to soil and land degradation can be traced to watershed management practices that are dictated by stakeholders' socio-economic circumstances. Of research interest, therefore, are studies on the appropriateness of different technologies given different physical and biological conditions of the soil. Technologies that address different bio-physical and socio-economic conditions among farmers might include re-vegetation, erosion control measures, water conservation, agroforestry systems, organic farming, and use of organic pesticides.

3. When developing plans for the watershed areas, addressing poverty and providing the means to make a living at the household level should be a major consideration, given our understanding of the relationships between land and water resources 
and the impacts of land use on water resources. Policymakers should understand, for example, that farming and fishing are very important to households since they provide a steady source of income despite their relatively small contribution to the family finances overall. It is therefore important to promote farm production and fishing practices that not only protect natural and environmental resources, but also improve households' levels of income. In addition, there should also be occupational opportunities for those children with better education who may decide to opt out of farming or fishing.

4. There is a need to assess household food risk as well as other forms of risk associated with the livelihoods of subwatershed residents. Households perceive that continued climatic events and other natural phenomena in the years to come will have a major impact on their incomes, family health, food security, and the community as a whole. Moreover, both the current study and previous studies have indicated that the incidence of food insecurity at the household level is influenced by such factors as the seasonality of farm income. This seasonality is in turn affected by the types of cropping systems employed and crops grown, the size of tilled land, poor harvests due to variable climate conditions, price volatility, and low food stocks.

5. Soil and water pollution, soil erosion and degradation, and adverse effects on health are also major issues faced by the communities in the study. Important questions that need to be answered are: What are the economic costs of soil erosion or degradation? What are the economic costs of ill health or sickness due to pollution? What economic and regulatory instruments can be instituted to reduce the level of soil and water pollution, soil erosion, and degradation? Determining the economic value of potential losses and gains from different measures is important for making policy and investment decisions to address environmental degradation.

Open Access This article is distributed under the terms of the Creative Commons Attribution Noncommercial License which permits any noncommercial use, distribution, and reproduction in any medium, provided the original author(s) and source are credited.

\section{References}

Food and Agriculture Organization-Food and Nutrition Division, Publishing Management Group (1997) Agriculture food and nutrition for Africa: a resource book for teachers of agriculture, p 116. http://www.fao.org/docrep/w0078e/w0078e00.HTM. Accessed 25 Aug 2013

National Statistical Coordination Board (2009) Philippines policy making and coordinating body on statistical matters. Philippine poverty statistics. http://www.nscb.org.ph

Rañola RF Jr, Rañola FM, Casin CS, Tan MFO (2010-2011) LakeHEAD progress report: the social and economic basis for managing environmental risk for sustainable food and health in watershed planning: the case of Silang-Sta. Rosa sub-watershed communities in Lake Laguna region. Research Institute for Humanity and Nature, Japan

Springer Editorial (2009) Food security and global environmental change: emerging challenges. Elsevier Environmental Science and Policy 12:373-377. http://www.elsevier.com/lacate/ envsci. Accessed 23 Aug 2013 